\title{
Design, Development and FEA of 3-Point Actuated Digging and Conveyor System for Self-Propelled Onion Harvester
}

\author{
${ }^{1}$ Sumedh Joshi , ${ }^{2}$ Sanket Sathe , ${ }^{3}$ Sarvesh Joshi, , ${ }^{4}$ Shubham Mhatre \\ ${ }^{1234}$ Student, Mechanical Department, Dr. Vishwanath Karad MIT World Peace University \\ Kothrud, Pune, India
}

\begin{abstract}
India is the second largest producer of onions in the world next to China. But the productivity of onions in India is very low i.e. 14.21 tons/ha. There is a huge requirement of man power and time, as harvesting of onions is a rigorous work. Our motive being to conceive, design, fabricate and develop "3-Point Actuated Self-propelled Onion Harvester" i.e. to develop a mechanized technique for onion harvesting which can run on vehicle power supply and won't require any other external power source. This system will have better performance in terms of productivity, fuel economy, operator comfort and reduce the damage to crops, human fatigue, and time. There are majorly two systems working simultaneously which are the digging system- to loosen the soil and get the onion bulbs out without damaging and conveying system that conveys the onion bulbs. Various factors are considered for designing such as type of soil, depth of onion bulbs, size of onion bulbs and damage to onion bulbs.
\end{abstract}

Keywords-1. 3 point actuator system 2.Self Propelled 3.Less damage to onion bulbs 4.Productivity 5.FEA Analysis

\section{INTRODUCTION}

Digging System scoops into the soil and pushes the onions and soil mass onto the conveying and windrowing system. This system loosens the soil and gets the onion bulbs out without damaging the onion. It consists of a trapezoidal scoop and Vshaped digging blade designed based on draft acting on it while harvesting the onion.

Conveying system was designed such that while the onion bulbs are segregated from soil mass while being conveyed at the end, to a predetermined height. The 3-point actitation system was designed to vary the digging depth of the system considering the variations in soil and onion bulb depth.

\section{DIGGING SYSTEM}

\section{A. Digging Scoop}

The digging scoop is a trapezoidal unit consisting of 10 evenly spaced blades. A brief study on onions led us to conclude that the average onion bulb diameter is around $60 \mathrm{~mm}$. Hence, we selected out depth of digging operation as $80 \mathrm{~mm}$ ensuring that the onion doesn't get damaged. These factors were considered to design the digging scoop.

1. Shape and Shape Factor - Onions can be considered as oblate or prolate.

$\mathrm{SF}=$ Equatorial Diameter / Polar Diameter

Shape Factor $>1$ for Oblate Onions

Shape Factor $<1$ for Prolate Onions

Here Equatorial diameter is the maximum diameter and polar diameter is the height of onion

2. Bulk Density - The weight of seed per unit volume $\mathrm{BD}=\mathrm{W} / \mathrm{V}$

$$
\begin{gathered}
\text { Where, } \mathrm{BD}=\text { Bulk density, } \mathrm{g} / \mathrm{cm}^{3} \\
\mathrm{~W}=\text { Weight of seeds, } \mathrm{g} \\
\mathrm{V}=\text { Volume of seeds }, \mathrm{cm}^{3}
\end{gathered}
$$

\section{Coefficient of static friction -}

The coefficient of static friction on mild steel for onion plant is equal to the tan of angle of static friction.

Coefficient of static friction $=\tan \varnothing$

Where $\varnothing$ is the angle of static friction.

4. Crushing resistance of onion bulb-The resistance of onion bulbs to deform or crush due to force applied upon them is called as the crushing resistance of onion bulb.

5. Bulk density of soil - It is defined as the mass of the dry soil per unit volume denoted by $\mathrm{p}$.

6. Cohesion and angle of internal friction-Cohesion is the property of materials to stick together to the same material. Angle of cohesion is found from the following equation -

$$
\mathrm{T}=\mathrm{C}+(\operatorname{sigma}) \tan \Phi
$$

Where, $\mathrm{T}=$ Shear stress

$$
\mathrm{C}=\text { cohesion }
$$$$
\text { sigma }=\text { normal stress }
$$

$\Phi=$ Angle of internal friction

7. Angle of soil metal friction - The angle at which the dynamic friction just starts between the metal and soil is defined as the angle of soil metal friction.

$$
\mu=\tan \delta
$$

Where, $\mu=$ friction coefficient

$\delta=$ Angle of soil-metal friction

Taking into account all the attributes, the blade geometry was selected with the help of "(1)"

$$
\mathrm{Pp}=\gamma \mathrm{z}_{1}^{2} \mathrm{~N}_{\gamma}+\mathrm{Cz}_{1} \mathrm{Nc}+\mathrm{Caz}_{1} \mathrm{Nca}+\mathrm{qz}_{1} \mathrm{Nq} \ldots
$$

Where,

$\mathrm{Pp}=$ Passive resistance of soil acting at angle of soil metal friction with the normal to interface $(\mathrm{kg} / \mathrm{m})$

$$
\begin{aligned}
& \gamma=\text { bulk density of soil }\left(\mathrm{kg} / \mathrm{m}^{2}\right) \\
& \mathrm{Z}_{1}=\text { depth of operation }(\mathrm{m}) \\
& \mathrm{Ca}=\text { soil interaction adhesion }\left(\mathrm{kg} / \mathrm{m}^{2}\right) \\
& \mathrm{q}=\text { Surcharge pressure on soil from surface } \\
& \text { above the failure plane }\left(\mathrm{kg} / \mathrm{m}^{2}\right)
\end{aligned}
$$

$\mathrm{N}_{\gamma}, \mathrm{Nc}, \mathrm{Nq}$ and $\mathrm{Nca}$ are the dimensionless less factor

These are the function of angle of shearing resistance of soil $(\Phi)$, angle of soil metal friction $(\delta)$ and geometry of loaded interface.

The corresponding assumptions were made-

1. Avg. bulk density of Soil i.e. $\gamma=1450 \mathrm{~kg} / \mathrm{m}^{3}$

2. Cohesion of Soil i.e. $\mathrm{C}=30.18 \mathrm{kN} / \mathrm{m}^{2}$

3. Adhesion of soil can be taken as 0 , i.e. 


$$
\mathrm{Ca}=0
$$

4. Friction $=0$ (as soil is scouring over the blade)

5. Surcharge of soil $=0$, i.e. $q=0$

6. Rake angle of digger blades $=15-25$ degree

Hence, Equation (1) can be simplified as-

$\mathrm{Pp}=\gamma \mathrm{z}_{1} \mathrm{~N}_{\gamma}+\mathrm{Cz}_{1} \mathrm{Nc} \ldots$ (2)

The values of $\mathrm{N}$-factor for inter-mediate degree of roughness of the interface were found by the equation -

$\mathrm{N} \delta=\mathrm{N} \delta=0 \frac{(\mathrm{N} \delta=\Phi)}{(N \delta=0)} \times \frac{\delta}{\Phi}$

Where,

$\mathrm{N} \delta=$ the required value of the appropriate $\mathrm{N}$-factors, $\mathrm{N} \delta=0$ and $\mathrm{N} \delta=\Phi=$ the corresponding value of the $\mathrm{N}$ - factor at $\delta=$ 0 and $\delta=\Phi$, respectively obtained from the appropriate chart $\Phi=15.64^{\circ}$

$\delta=29^{\circ}$,

$\alpha=20^{\circ}$

$\mathrm{Z}_{1}=0.8 \mathrm{~m}$

From these values we calculated the following values

$$
\begin{aligned}
& \mathrm{N}_{\gamma}=1.55 \\
& \mathrm{~N}_{\gamma}=1.75 \\
& \mathrm{Nc}=1.65 \\
& \mathrm{Nc}=1.60
\end{aligned}
$$

Substituting these values in "(2)", we obtained the value of Pp which comes out to be $4.02234 \mathrm{kN} / \mathrm{m}$. The total width of the digger scoop was $0.85 \mathrm{~m}$ so we found the effective Pp to be $3.419 \mathrm{kN} / \mathrm{m}$.

The passive resistance Pp was acting at an angle of friction( $\delta$ ) with normal to the interface.

Therefore, Force component parallel to the digger scoop face -

Pp1 $=4.022 \times \cos (74.36)=1.084 \mathrm{kN}$

Force component perpendicular to the digger scoop face -

$\mathrm{Pp} 2=4.022 \times \cos (15.64)=3.8730 \mathrm{kN}$

These force components were used to design the digger scoop and the FEA was also performed.

The thickness of the digger scoop was decided by closely studying other agricultural diggers and a thickness range between $5 \mathrm{~mm}$ to $8 \mathrm{~mm}$ was obtained. Later, FEA was performed on these models and the digger scoop with $5 \mathrm{~mm}$ thickness was selected. The $5 \mathrm{~mm}$ thickness model was lightweight and safe for the operation. A $1 \times 1 \mathrm{~m}$ MS sheet was laser cut into the required shape and the blades were given an angle of $20^{\circ}$ by hydraulic bending. This digger was then bolted to the side support members.

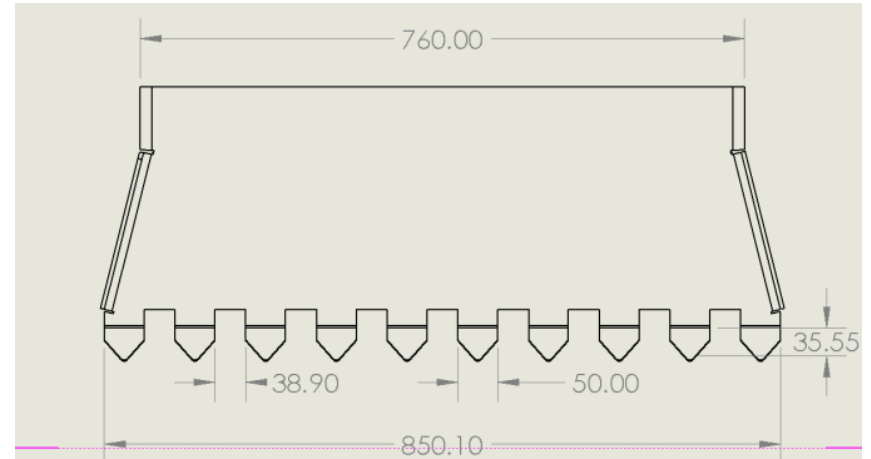

Fig (1) - Top View of the Digger scoop (dimensions are in $\mathrm{mm}$ )

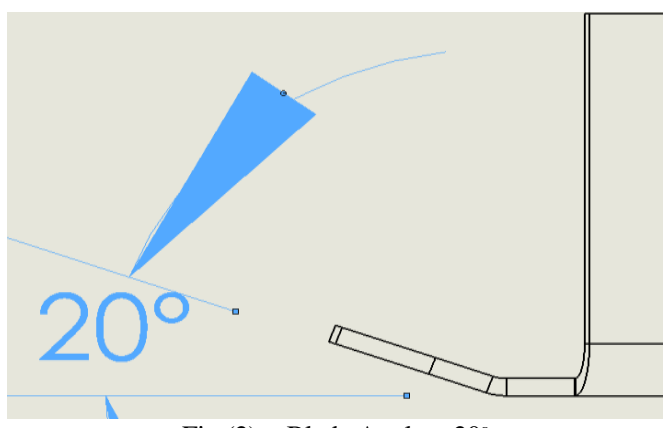

Fig (2) - Blade Angle $=20^{\circ}$

Table (1) - Digging System Specifications

\begin{tabular}{|c|c|}
\hline Material & Mild Steel(ASTM 1006) \\
\hline Number of Blades & 10 (evenly spaced) \\
\hline Blade Geometry & $50 \times 70 \times 5 \mathrm{~mm}$ \\
\hline Shear Blade Rake Angle & $20^{\circ}$ \\
\hline Harvesting Width & $850 \mathrm{~mm}$ \\
\hline Depth of Digging & 8 \\
\hline Thickness & $5 \mathrm{~mm}$ \\
\hline
\end{tabular}

\section{B. FEA Analysis of Digger Scoop}

FEA of the Digger Scoop was performed and the most optimum design was selected. Scoop iterations of thickness $5 \mathrm{~cm}, 6 \mathrm{~cm}, 7 \mathrm{~cm}$ and $8 \mathrm{~cm}$ were selected and the analysis was performed.

The analysis included the various factors like equivalent stress, total deflection and equivalent strain. Loads Pp1 and Pp2 were applied to the models and results were obtained. ANSYS $®$ R18.2 version was used.

Table (2) - Material Properties

\begin{tabular}{|c|c|}
\hline Material & ASTM Steel 1006 \\
\hline Young's Modulus (E) & $200 \mathrm{GPa}$ \\
\hline Density & $7896 \mathrm{~kg} / \mathrm{m}^{3}$ \\
\hline Poisson's Ratio & 0.29 \\
\hline Shear Modulus & $7.751 \mathrm{E}+10 \mathrm{~Pa}$ \\
\hline Bulk Modulus & $1.587 \mathrm{E}+11 \mathrm{~Pa}$ \\
\hline
\end{tabular}

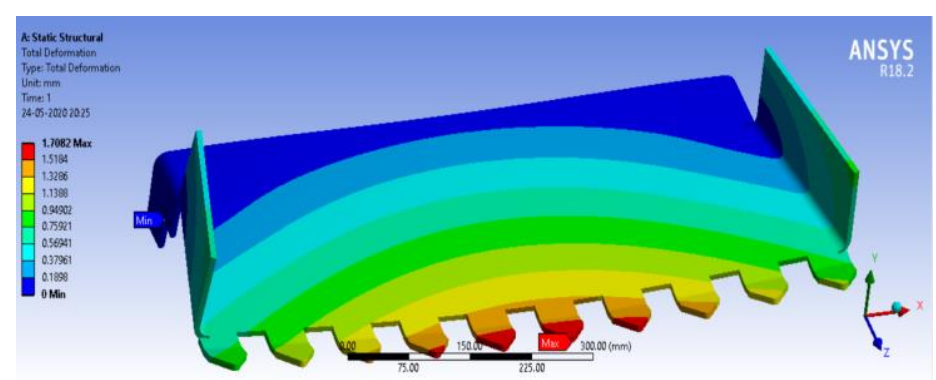

Fig (3) - Total Deformation Analysis for $5 \mathrm{~mm}$ Thickness 


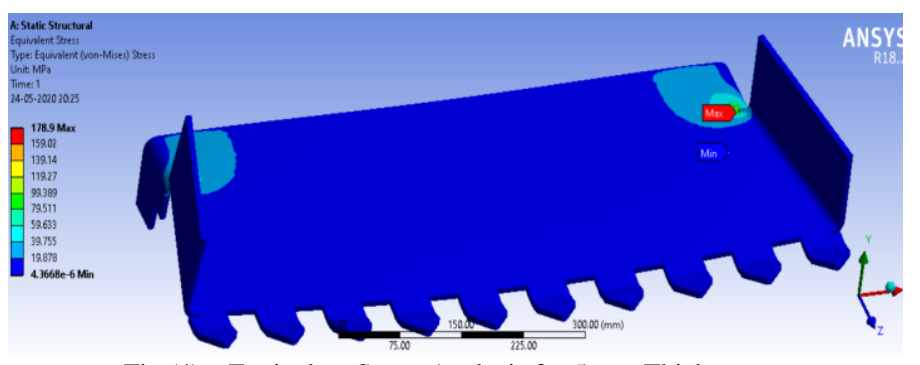

Fig (4) - Equivalent Stress Analysis for 5 mm Thickness

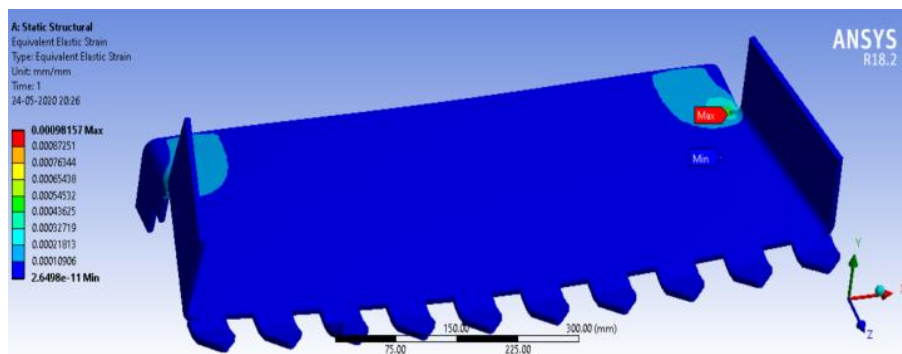

Fig (5) - Equivalent Strain Analysis for $5 \mathrm{~mm}$ Thickness

Analysis of all the models was done and the following results were obtained.

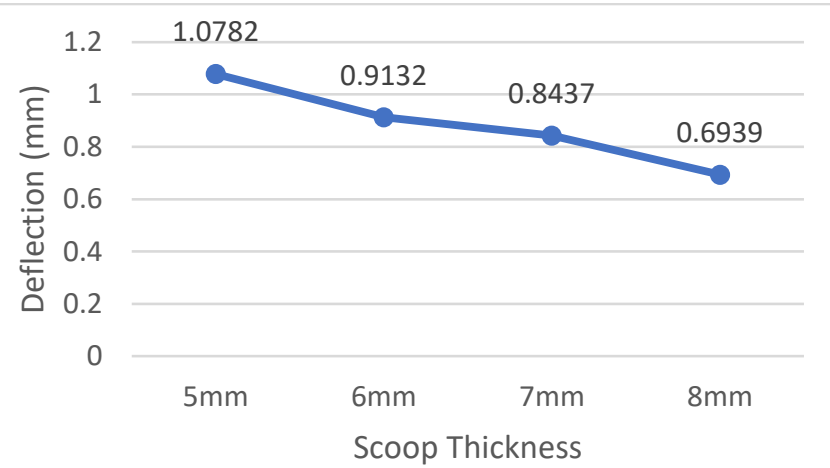

Fig (6) - Variation of Deflection(mm) with Scoop Thickness (mm)

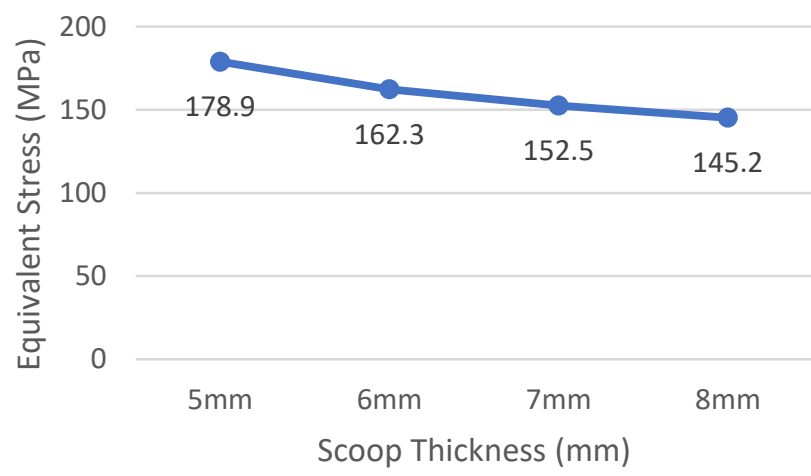

Fig (7) - Variation of Equivalent Stress (MPa) with Scoop Thickness (mm)

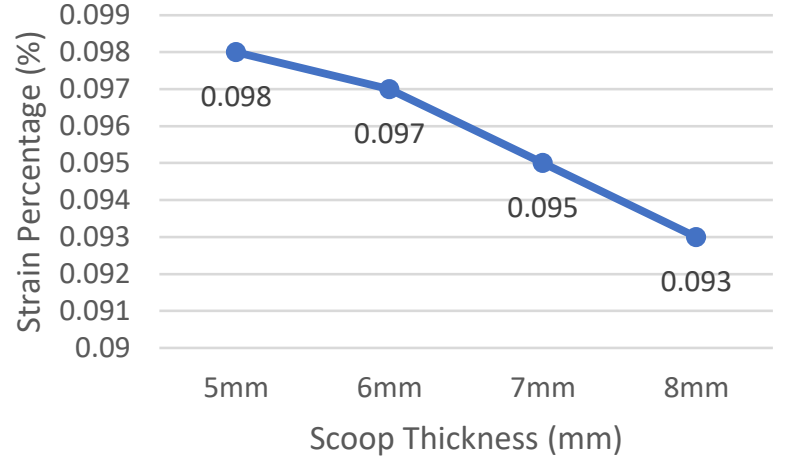

Fig (8) - Variation of Equivalent Strain Percentage (\%) with Scoop Thickness (mm)

Table (3) - Variation of weight with thickness

\begin{tabular}{|c|c|}
\hline Scoop Thickness & Weight \\
\hline $5 \mathrm{~mm}$ & $14.92 \mathrm{~kg}$ \\
\hline $6 \mathrm{~mm}$ & $17.9 \mathrm{~kg}$ \\
\hline $7 \mathrm{~mm}$ & $20.88 \mathrm{~kg}$ \\
\hline $8 \mathrm{~mm}$ & $23.87 \mathrm{~kg}$ \\
\hline
\end{tabular}

From the above results, the $5 \mathrm{~mm}$ thickness model of the digger scoop was selected. The $5 \mathrm{~mm}$ thickness model weighed less and could sustain the soil draft load without failing.

\section{CONVEYING SYSTEM}

The conveying system is used to transfer the onions from the digger scoop to the rear outlet of the system. This system consists of 2 EN8 shafts that were designed by ASME standards. A Stainless-Steel honeycomb mesh belt was used to convey the onions. This belt was selected by taking into account the extent of damage different honeycomb belts might cause to the onions and the maximum sustainable load that a belt can bear. The belt mesh spacing was about $3 \mathrm{~cm}$ to ensure that the onions don't pass through it. The chain and sprockets were designed to sustain the maximum draft load of the soil and onions.

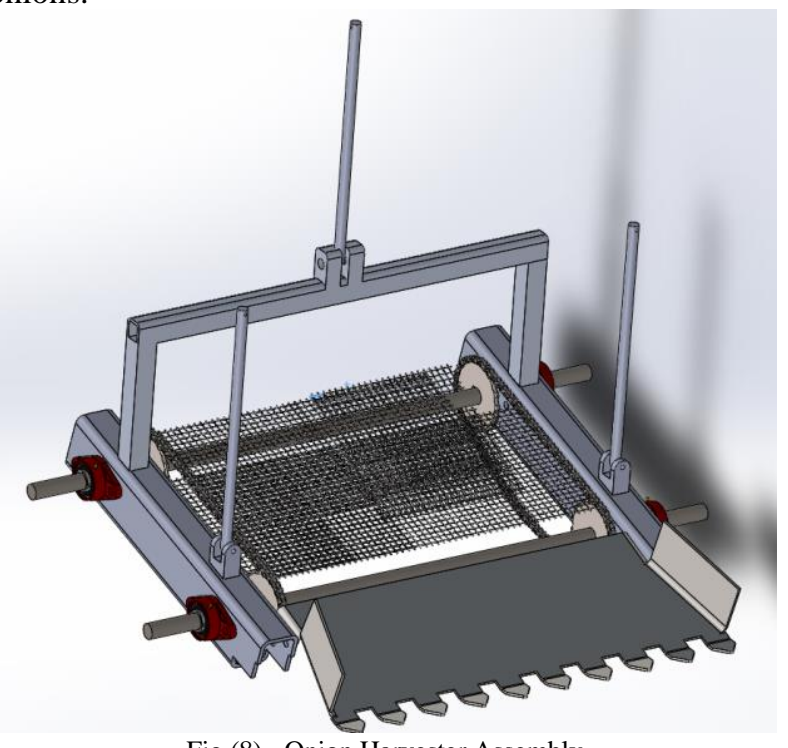

Fig (8) - Onion Harvester Assembly

The conveyor was designed to work at an angle of $17^{\circ}$ to ensure maximum efficiency and minimal damage to the onion bulbs. 
Table (3) - Conveying System Specifications

\begin{tabular}{|c|c|}
\hline Term & Specification \\
\hline Conveyor Belt Material & Stainless Steel \\
\hline Shaft Material & EN8 \\
\hline Shaft Diameter & $30 \mathrm{~mm}$ \\
\hline Speed of Conveyor & $3.13 \mathrm{~m} / \mathrm{s}$ \\
\hline Length of Conveyor & $553 \mathrm{~mm}$ \\
\hline Width of Conveyor & $740 \mathrm{~mm}$ \\
\hline Angle of Conveyor & $17^{\circ}$ \\
\hline Material Handling Capacity & $0.0993 \mathrm{~m}^{3} / \mathrm{s}$ \\
\hline Power Consumption & $1.08 \mathrm{HP}$ \\
\hline Sprocket Pitch & $12.7 \mathrm{~mm}$ \\
\hline No. of chain links & 56 \\
\hline
\end{tabular}

IV. 3 POINT ACTUATED SYSTEM

The entire harvester system was made electrically adjustable with the help of 3 linear actuators. The average depth of the onion bulb inside the soil ranges from $6 \mathrm{~cm}$ to $8 \mathrm{~cm}$. To achieve maximum efficiency and to reduce the damage caused to the onion bulb, the depth of digging operation could be changed. These actuators were selected on the basis of maximum load capacity. An electronic framework was provided to control the motion of these actuators. The 2 front actuators were used to change the conveyor angle and all 3 were actuated to achieve height control. This system was powered from the vehicle battery.

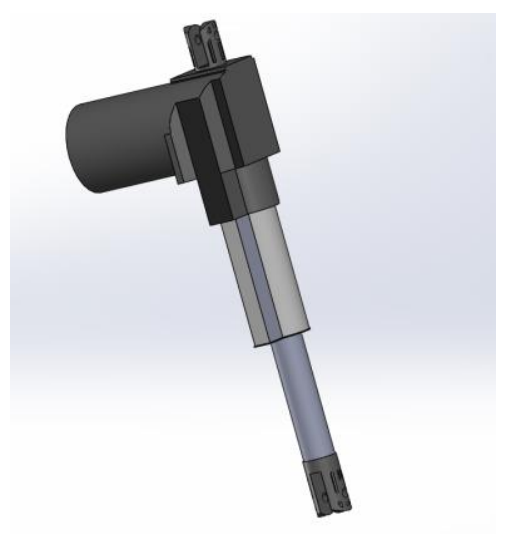

Fig (9) - Linear Actuator

JIECANG® JC35L18 actuators were selected for this purpose.

Table (4) - Specifications of JIECANG® JC35L18

\begin{tabular}{|c|c|}
\hline Load thrust & $8000 \mathrm{~N}$ \\
\hline Max. load pull & $4000 \mathrm{~N}$ \\
\hline Max IP rating & IPX6W \\
\hline Stroke length & $50-500 \mathrm{~mm}( \pm 2 \mathrm{~mm}) 8000 \mathrm{~N}$ \\
\hline Noise level & $48 \mathrm{~dB}($ ambient level $\leq 35 \mathrm{~dB})$ \\
\hline Motor & $24 \mathrm{~V}$ DC permanent magnet \\
\hline
\end{tabular}

V. CONCLUSIONS

It is clearly evident that Indian farmers are facing a shortage of labor and efficient farming solutions. There are very less mechanized options in the onion sector. FEA of the digger scoop was performed and the most optimum and lightweight design was selected. The actuator system was tested and tuned for accurate response. Hence, the 3-point actuated selfpropelling onion harvester was designed to modernize this sector and increase the productivity while ensuring minimum damage to the onion crop.

\section{ACKNOWLEDGEMENTS (OPTIONAL)}

The author can acknowledge any person and authority in this section. This is not Mandatory

\section{REFERENCES}

[1] Tapan Kumar Khura, "Design and Development of Tractor Drawn Onion Digger", Division of Agricultural Engineering Indian Agricultural Research Institute, New Delhi. Year 2008.

[2] Ashwini Talokar, Kanchan Wankhade, \& V. P. Khambalkar, "Design of Onion Harvester" International Journal and Magazine of Engineering, Technology, Management and Research, Jan 2014

[3] Jafar Massah, Ahmad Lotfi, Akbar Arabhosseini, "Effect of Blade Angle and Speed of Onion Harvester on Mechanical Damage of Onion Bulbs", Ama, Agricultural Mechanization in Asia, Africa \& Latin America 43(3):60-63, June 2012.

[4] O.A. Omar, Soha G. Abdel Hamid and G.A. El-Termzy, "Development of an onion crop harvester", Misr J. Ag. Eng., 35 (1): 39 - 56, Jan 2018

[5] Sungha Hong, Kyouseung Lee, Yongjin Cho, Wonyeop Park, "Development of Welsh Onion Harvester for Tractor", Journal of Biosystems Engineering, Volume 39 Issue 4 / Pages.290-298 / 2014

[6] Sunil Shirwal, Indra Mani, N. P. S. Sirohi \& Adarsh Kumar "Development \& Evaluation of Carrot Harvester", Agricultural Mechanization in Asia, Africa \& Latin America, Dec-2015.

[7] Sunil Pareek, Sunil Sharma, Vinay Kumar, Narashans Alok Sagar, "Onion (Allium cepa L.)", Fruit and Vegetable Phytochemicals: Chemistry and Human Health, Edition: Second, Publisher: Wiley Blackwell, John Wiley \& Sons Ltd., Editors: ElhadiM.Yahia, pp.1145-1161 (16), May 2017.

[8] Pham Hoang, "Design and simulation of micro-linear actuator", 2010 IEEE Conference on Robotics, Automation and Mechatronics, July 2010

\section{BIOGRAPHIES}

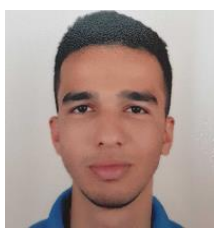

Sumedh P. Joshi, pursuing third year in Bachelor of Mechanical Engineering from Dr. Vishwanath Karad MIT World Peace University, Pune, Maharashtra, India.

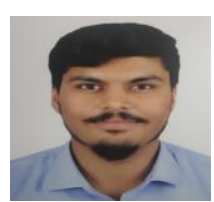

Sanket N. Sathe, pursuing third year in Bachelor of Mechanical Engineering from Dr. Vishwanath Karad MIT World Peace University, Pune, Maharashtra, India.

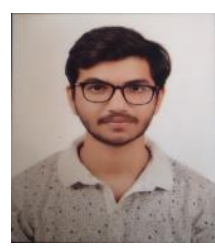

Sarvesh P. Joshi, pursuing third year in Bachelor of Mechanical Engineering from Dr. Vishwanath Karad MIT World Peace University, Pune, Maharashtra, India.

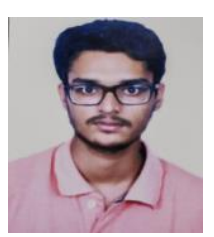

Shubham K. Mhatre, pursuing third year in Bachelor of Mechanical Engineering from Dr. Vishwanath Karad MIT World Peace University, Pune, Maharashtra, India. 